\title{
Elevated c-Src Tyrosine Kinase Activity in Premalignant Epithelia of Ulcerative Colitis
}

Christine A. Cartwright, * Carol A. Coad, ${ }^{*}$ and Barbara M. Egbert ${ }^{\star}$

*Department of Medicine, Stanford University, Stanford, California 94305; and ${ }^{\ddagger}$ Department of Pathology, Veterans Administration Medical Center, Palo Alto, California 94304

\begin{abstract}
Ulcerative colitis (UC) is a chronic inflammatory disease of the colon with a high incidence of colon cancer. Dysplasia is a precursor to carcinoma and a predictor of malignant potential; epithelia containing high-grade or severe dysplasia is most likely to develop cancer. The cellular oncogene c-src and its viral homologue v-src (the transforming gene of Rous sarcoma virus) encode 60-kD cytoplasmic, membrane-associated protein tyrosine kinases. For the viral protein or transforming mutants of the cellular protein (Src), a close correlation exists between elevated tyrosine kinase activity and malignant transformation of cells. Previously, we and others observed elevated Src activity in sporadic colon carcinomas and benign adenomas at greatest risk for developing cancer (those with large size, villous architecture, and/or severe dysplasia). Here we report that Src activity and protein abundance are also elevated in neoplastic UC epithelia. Activity is highest in malignant and severely dysplastic epithelia, and 6-10-fold higher in mildly dysplastic than in nondysplastic epithelia. Thus, Src activity is elevated in premalignant UC epithelia, which is at greatest risk for developing cancer. The data suggest that activation of the src proto-oncogene is an early event in the genesis of UC colon cancer. ( $J$. Clin. Invest. 1994. 93:509-515.) Key words: oncogene $\bullet$ protein kinase $\bullet$ colon cancer $\cdot$ dysplasia
\end{abstract}

\section{Introduction}

Colon carcinoma is the most common gastrointestinal cancer and the second most common cancer overall in the United States (1). The estimated 152,000 new cases and 57,000 deaths from the disease during 1993 alone illustrate its impact on cancer-associated morbidity and mortality. The risk of colon cancer is particularly high in ulcerative colitis (UC), ${ }^{1}$ a chronic inflammatory disease of the colon. The cumulative risk is $0.5-$ $1 \% / \mathrm{yr}$ after the first $10 \mathrm{yr}$ of disease (e.g., $10-20 \%$ after $30 \mathrm{yr}$ of colitis involving the entire colon ) and the relative risk is 15 -fold higher than expected in age-matched populations without colitis $(2,3)$.

Address correspondence to Dr. Christine Cartwright, Medical School Lab Surge Building, P304, Stanford University School of Medicine, Stanford, CA 94305-5487.

Received for publication 6 July 1993 and in revised form 23 September 1993.

1. Abbreviations used in this paper: DALM, high-grade dysplasia-associated lesion or mass; HGD, high-grade dysplasia; LGD, low-grade dysplasia; UC, ulcerative colitis.

The Journal of Clinical Investigation, Inc.

Volume 93, February 1994, 509-515
The cellular oncogene c-src and its viral homologue v-src (the transforming gene of Rous sarcoma virus) encode 60-kD cytoplasmic, membrane-associated, protein tyrosine kinases (4-8). For the viral protein ( $\mathrm{v}-\mathrm{Src}$ ) or transforming mutants of the cellular protein $(\mathrm{Src})$, a close correlation exists between elevated tyrosine kinase activity and malignant transformation of cells. Src activity is elevated in three human cancers: colon and breast adenocarcinomas, and neuroblastoma (9-12). Previously, we observed that Src from 13 of 21 primary colon carcinomas had 5-7-fold higher activity than Src from normal adjacent mucosa. Similarly, Src from 6 of 9 colon carcinoma cell lines had 5-20-fold higher activity than that from normal colonic cells (12). Moreover, only those colon carcinoma cell lines with elevated Src activity had elevated levels of three phosphotyrosine-containing proteins, thereby suggesting a functional correlation for the increased Src tyrosine kinase activity. We also observed increased Src activity in colonic adenomas containing focal carcinoma, and in benign adenomas at greatest risk for developing cancer (those with large size, villous architecture, and/or severe dysplasia ) (13). Interestingly, segments of fetal rat colon infected with a v-src-containing retrovirus and implanted in syngeneic pups developed significant dysplasia throughout the colonic epithelia (14).

Dysplasia is a precursor to carcinoma in adenomas and in UC. To determine whether Src activity is elevated in precancerous UC tissue as it is in adenomas, we measured its kinase activity in normal, acute or chronically inflamed, dysplastic and malignant epithelia from 35 UC patients. Src activity in malignant or dysplastic epithelia was significantly higher than that in nondysplastic epithelia from the same individual. Moreover, the level of Src activity in dysplastic epithelia correlated with the degree of dysplasia: the more severe the dysplasia, the higher the Src activity.

\section{Methods}

Patients and tissue collection. Colonic mucosal samples were obtained from individuals with $\mathrm{UC}$ for $\geq 10 \mathrm{yr}$. Specimens were collected during colectomy or colonoscopy for cancer surveillance. Mucosal samples were obtained at $10-\mathrm{cm}$ intervals throughout the colon and divided into two parts. One part was formalin fixed and analyzed microscopically, the other part was frozen in liquid nitrogen (within $1 \mathrm{~min}$ if collected during colonoscopy; within 10 min if collected surgically) and analyzed for Src protein levels and tyrosine kinase activity. The protocol was approved by the institutional administrative panel on human subjects in medical research, and informed written consent was obtained from all patients.

Histopathology. Specimens were independently analyzed by two staff pathologists. Both pathologists were blinded to the Src kinase assay results. Pathologic classifications were those of Riddell et al. (15). Definitions used are: mild quiescent colitis: increased numbers of lymphocytes, plasma cells, eosinophils, and macrophages in the lamina propria; severe quiescent colitis: dense mononuclear cell infiltrates (predominantly lymphocytes and plasma cells), distorted crypt architec- 
ture with branched or irregular glands, crypt atrophy, and goblet cell mucin depletion; active colitis: polymorphonuclear cell infiltration into the lamina propria, often with crypt injury (cryptitis, crypt ulcer, or crypt abscess), epithelial destruction, and concurrent regeneration; chronic active colitis: mixed active colitis, destruction, regeneration, and resolving colitis; dysplasia: neoplastic epithelial proliferation with enlarged irregular hyperchromatic crowded and stratified nuclei extending halfway (mild or low-grade dysplasia [LGD]), or more than halfway (severe or high-grade dysplasia [HGD]), toward the luminal surface of the cell; invasive adenocarcinoma: malignant glandular epithelium extending through the muscularis mucosae. With the exception of patient 5, who had HGD or carcinoma in situ in a cecal mass, both pathologists agreed on histopathologic diagnoses. Of note, many morphologists use the term HGD synonymously with carcinoma in situ to indicate the malignant nature of these cells (15).

Protein extractions, immunoprecipitations, and tyrosine kinase assays. Tissues were homogenized in Kontes glass tissue grinders and cells were lysed in ice-cold, modified RIPA buffer $(0.1 \%$ SDS, $1 \%$ NP$40,1 \%$ sodium deoxycholate, $0.15 \mathrm{M}$ sodium chloride, $10 \mathrm{mM}$ sodium phosphate [pH 7.0], $100 \mu \mathrm{M}$ sodium vanadate, $50 \mathrm{mM}$ sodium fluoride, $50 \mu \mathrm{M}$ leupeptin, $1 \%$ aprotinin, $2 \mathrm{mM}$ EDTA, and $1 \mathrm{mM}$ dithiotreitol). Lysates were centrifuged at $29,000 \mathrm{~g}$ for $1 \mathrm{~h}$ at $4^{\circ} \mathrm{C}$ and protein concentrations were measured by the BCA protein assay (Pierce, Rockford, IL). Lysate containing $90 \mu \mathrm{g}$ protein was incubated with excess mAb specific for Src ( $m A b 327)$ (16), or with rabbit anti-peptide antibody specific for a Src-related tyrosine kinase, c-Yes (17). Excess affinity-purified rabbit anti-mouse immunoglobulin G (Cooper Biomedical, Malvern, PA) was added to mAb 327 precipitates. For in vitro protein-tyrosine kinase reactions ( 18-22), immunoprecipitates were incubated for $15 \mathrm{~min}$ at $30^{\circ} \mathrm{C}$ in $30 \mu \mathrm{l}$ of buffer containing $50 \mathrm{mM}$ piperazine- $N$ - $N^{\prime}$-bis (2-ethanesulfonic acid) ( $\mathrm{pH} \mathrm{7.0),}$ $10 \mathrm{mM}$ manganese chloride, $10 \mathrm{mM}$ dithiothreitol, $1 \mu \mathrm{g}$ acid-denatured rabbit muscle enolase (23) (Boehringer Mannheim Biochemicals, Indianapolis, IN), and $50 \mu \mathrm{Ci}$ of $\gamma$-[ $\left.{ }^{32} \mathrm{P}\right] \mathrm{ATP}(4,000 \mathrm{Ci} / \mathrm{mmol}$; ICN, Costa Mesa, CA $)$. Adding unlabeled ATP $(20 \mu \mathrm{M})$ and/or incubating samples for $10 \mathrm{~min}$ gave similar results. c-Src in vitro protein kinase activity is linearly related to the concentration of total cellular protein $(12,13)$. Proteins were resolved by $7 \%$ SDS-PAGE and gels were stained with Coomassie brilliant blue G-250 (Bio-Rad Laboratories, Richmond, CA) to confirm that equivalent amounts of enolase were present in each lane. Radiolabeled proteins were detected using Kodak XAR film and an intensifying screen at $-80^{\circ} \mathrm{C} .{ }^{32} \mathrm{P}$ incorporation into proteins was quantified by Cerenkov counting. Quantitation by liquid scintillation spectroscopy after gel pieces are dissolved in 1.2 $\mathrm{ml}$ of $30 \% \mathrm{H}_{2} \mathrm{O}_{2} / 70 \%$ perchloric acid $(2: 1)$ at $55^{\circ} \mathrm{C}$ for $12 \mathrm{~h}$ gives similar results $(12,13)$.

Immunoblot analysis. mAb 327 immunoprecipitates, prepared in parallel with those used for in vitro protein kinase assays, were resolved by $7 \%$ SDS-PAGE. Proteins were transferred to nitrocellulose membranes $(0.45 \mu \mathrm{m}$; Schleicher \& Schuell, Inc., Keene, $\mathrm{NH})$ in transfer buffer ( $12.5 \mathrm{mM}$ Tris- $\mathrm{HCl}$ [pH 8.3], $100 \mathrm{mM}$ glycine, and $20 \%$ methanol) using a Trans-Blot apparatus (Bio-Rad Laboratories) for $4 \mathrm{~h}$ at 40 $\mathrm{V}(12,13)$. Membranes were incubated overnight in blocking buffer containing TNE ( $10 \mathrm{mM}$ Tris- $\mathrm{HCl}$ [pH 7.5], $50 \mathrm{mM} \mathrm{NaCl}, 2.5 \mathrm{mM}$ EDTA, and $0.01 \% \mathrm{NaN}_{3}$ ), $0.1 \%$ ( $\mathrm{vol} / \mathrm{vol}$ ) Tween 20 (Sigma Chemical Co., St. Louis, MO), and 5\% nonfat powdered milk. After blocking, membranes were incubated for $2 \mathrm{~h}$ with normal sheep serum (Cooper Biomedical) (1:10 dilution in blocking buffer), then for $1 \mathrm{~h}$ with puri- fied mAb 327 ascites (1:250 dilution in blocking buffer) at $22^{\circ} \mathrm{C}$. Under these conditions antibody was in excess of antigen. Membranes were washed in TNE buffer with changes every $10 \mathrm{~min}$ for $1 \mathrm{~h}$ before incubating with excess ${ }^{125}$ I-labeled affinity-purified, sheep anti-mouse IgG (New England Nuclear, Boston, MA) $\left(10^{6} \mathrm{cpm} / \mathrm{ml}\right.$ blocking buffer) for $1 \mathrm{~h}$ at $22^{\circ} \mathrm{C}$. After washing in TNE buffer for $1 \mathrm{~h},{ }^{125}$ I-labeled proteins were visualized by autoradiography with an intensifying screen at $-80^{\circ} \mathrm{C}$, and quantified by counting excised bands. The amount of Src protein detected in lysates is linear over a fivefold range of total cellular protein $(12,13)$.

\section{Results}

To determine whether Src activity is elevated in dysplastic UC epithelia as it is in dysplastic polyps, we collected colonic mucosal samples from $35 \mathrm{UC}$ patients and analyzed tissue for histopathology (Table I) and Src in vitro protein-tyrosine kinase activity (Figs. 1-5). 8 patients had 27 samples of normal epithelia proximal to the involved UC epithelia, 16 had 39 samples of active colitis, 27 had 118 samples of mild quiescent colitis, 8 had 21 samples of severe quiescent colitis, 4 had 10 samples of LGD, 3 had 11 samples HGD, and 2 had invasive carcinoma. Src activity measured in samples from seven representative patients is shown:

Src tyrosine kinase activity in active or quiescent UC. Patient 1 (Fig. $1 A$ ) had left-sided, distal UC involving the rectosigmoid colon for $\geq 13 \mathrm{yr}$. Normal epithelia was present in the proximal colon (ascending, transverse, and descending colon), mild quiescent colitis in the sigmoid colon, and moderate-tosevere active colitis in the rectum. Src kinase activity varied little between different regions of normal epithelium (compare lanes 1-4). Moreover, Src activity varied little between normal epithelia and that containing mild quiescent colitis (compare lanes 1-4 with lane 5), or that containing moderate-to-severe active colitis (compare lanes $1-4$ with lane 6 ). Thus, in this individual and others, Src activity in active or mild quiescent colitis was similar to that in normal epithelia.

Patient 2 (Fig. $1 B$ ) had universal UC (involving the entire colon) for $13 \mathrm{yr}$. The ascending, transverse, descending, and proximal sigmoid colon contained mild quiescent colitis. The distal sigmoid colon and rectum contained severe quiescent colitis. Src activity varied little between different regions of mild quiescent colitis (compare lanes 1-5). In contrast, Src activity in severe quiescent colitis (lanes 6 or 7) was two- to threefold higher than that in mild quiescent colitis (lanes 1-5).

Src tyrosine kinase activity in dysplastic UC epithelia. $\mathrm{Pa}$ tient 3 (Fig. $2 A$ ) had universal UC for $11 \mathrm{yr}$. Severe quiescent colitis was present throughout the colon. In addition, mild dysplasia or LGD was present in the right colon (cecum, ascending, and proximal transverse colon ). Src activity in the dysplastic epithelia (lanes 1-3) was, on average, threefold higher as measured by enolase phosphorylation or fivefold higher as measured by autophosphorylation than Src activity in the nondysplastic severe quiescent colitis (lanes 4-8).

Table I. Histopathology of Colonic Mucosa from UC Patients

\begin{tabular}{|c|c|c|c|c|c|c|c|}
\hline & Normal & $\begin{array}{l}\text { Active } \\
\text { colitis }\end{array}$ & $\begin{array}{l}\text { Quiescent } \\
\text { (mild) }\end{array}$ & $\begin{array}{l}\text { Quiescent } \\
\text { (severe) }\end{array}$ & LGD & HGD & Cancer \\
\hline Patients & 8 & 16 & 27 & 8 & 4 & 3 & 2 \\
\hline Samples & 27 & 39 & 118 & 21 & 10 & 11 & 2 \\
\hline
\end{tabular}




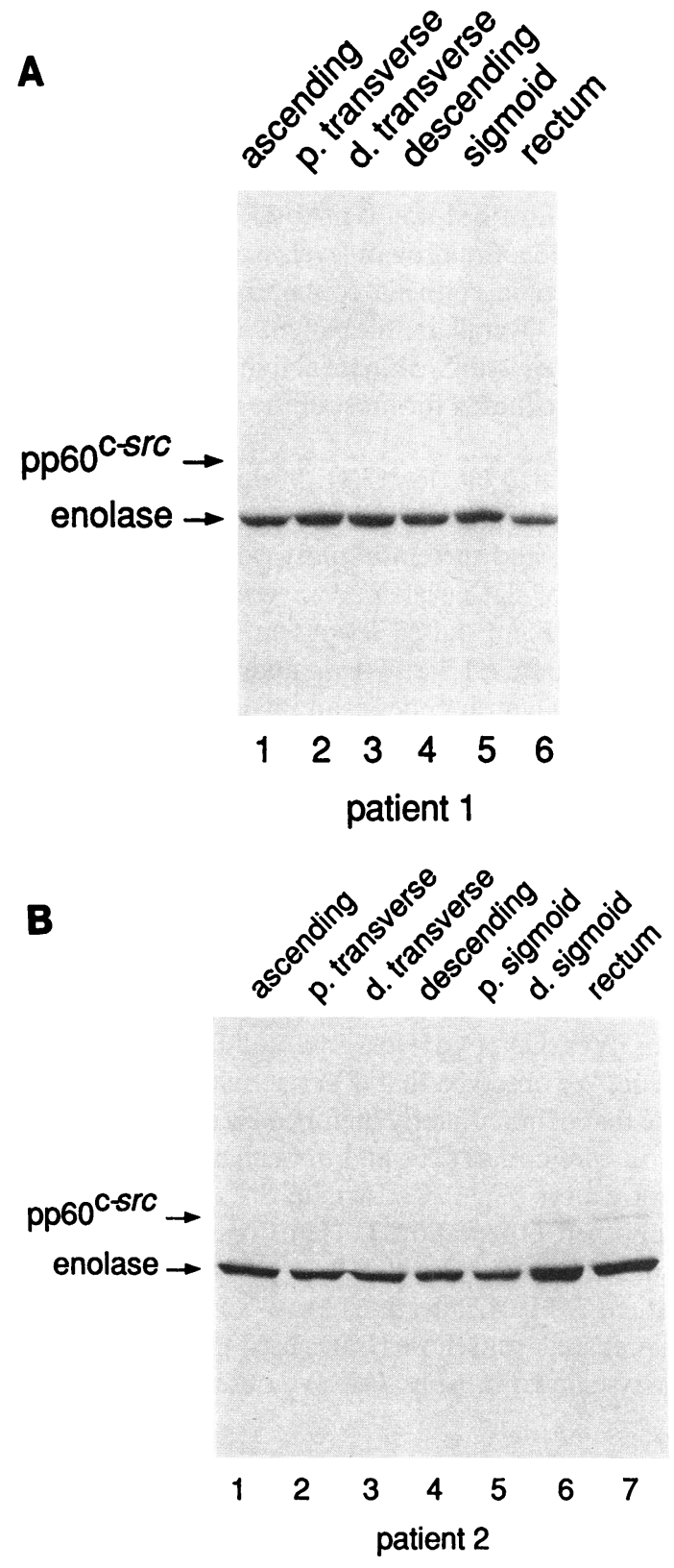

Figure 1. Src tyrosine kinase activity in active or quiescent UC. $(A)$ Patient 1: lanes 1-4, normal epithelia; lane 5, mild quiescent colitis; lane 6, moderate-to-severe active colitis. $(B)$ Patient 2: lanes 1-5, mild quiescent colitis; lanes 6 and 7, severe quiescent colitis. Mucosal samples were homogenized and cell lysates containing $90 \mu \mathrm{g}$ of protein were prepared. Proteins were immunoprecipitated with excess mAb 327, incubated with $\gamma-\left[{ }^{32} \mathrm{P}\right] \mathrm{ATP}$ and enolase, and resolved by SDS-PAGE. Autoradiogram exposure times at $-80^{\circ} \mathrm{C}$ with intensifying screens: $(A) 20 \mathrm{~min}$; $(B) 15 \mathrm{~min}$. pp60 $0^{c-s r c}$, c-Src; $p$., proximal; $d$., distal.

Patient 4 (Fig. $2 B$ ) had universal UC for 26 yr. Mild quiescent colitis was present throughout the colon. In addition, LGD was present in the rectal epithelium and in a small, rectal adenoma. Src activity in either region containing LGD (lane 2 or 3 ) was five- or sevenfold higher (as measured by enolase or autophosphorylation, respectively) than Src activity in the nondysplastic quiescent colitis (lane 1). A phosphorylated protein with an approximate molecular mass of $65-70 \mathrm{kD}$ ( arrowhead) was detected in lanes 2 and 3 . This protein was reprodu- cibly detected in dysplastic epithelia from this patient, and rarely in others. Its identity is being investigated.

Patient 5 (Fig. 2 B) had universal UC for 19 yr. The entire colon contained mild quiescent colitis. In addition, a large mass measuring $5 \mathrm{~cm}$ in diameter was present in the cecum. Six biopsies of the lesion all showed HGD as read by one pathologist or carcinoma in situ as read by the second pathologist. Src activity in the mass (lane 5) was 23- or 21 -fold higher than that in adjacent nondysplastic quiescent colitis (lane 4). After surgical resection of the cecal mass, HGD or carcinoma in situ was again found throughout the lesion.

Src tyrosine kinase activity in UC carcinoma. Patient 6 (Fig. 3) had universal UC for $16 \mathrm{yr}$. All biopsies obtained at colonoscopy and later at colectomy contained dysplasia. LGD
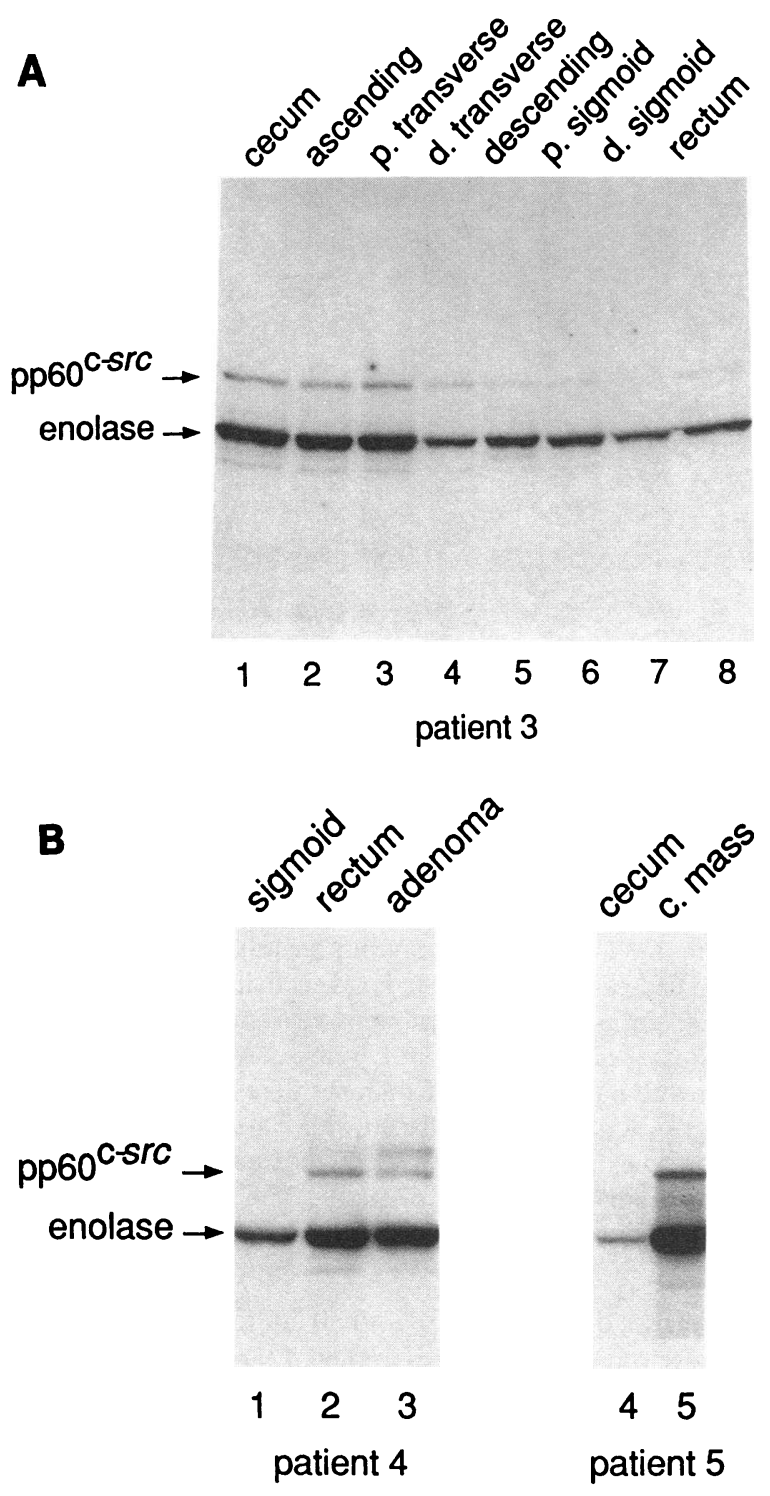

Figure 2. Src tyrosine kinase activity in dysplastic UC epithelia. $(A)$ Patient 3: lanes $1-3$, LGD; lanes 4-8, severe quiescent colitis. $(B)$ Patient 4: lane 1 , mild quiescent colitis; lanes 2 and 3, LGD. Patient 5: lane 4, mild quiescent colitis; lane 5, HGD or carcinoma in situ. mAb 327 immune complex protein kinase reactions were performed as described in the legend to Fig. 1 . Exposure times at $-80^{\circ} \mathrm{C}$ with intensifying screens: $(A) 18 \mathrm{~min} ;(B)$ lanes $1-3,10 \mathrm{~min}$; lanes 4 and 5,20 min. $p$., proximal; $d$., distal; $c$., cecal. 

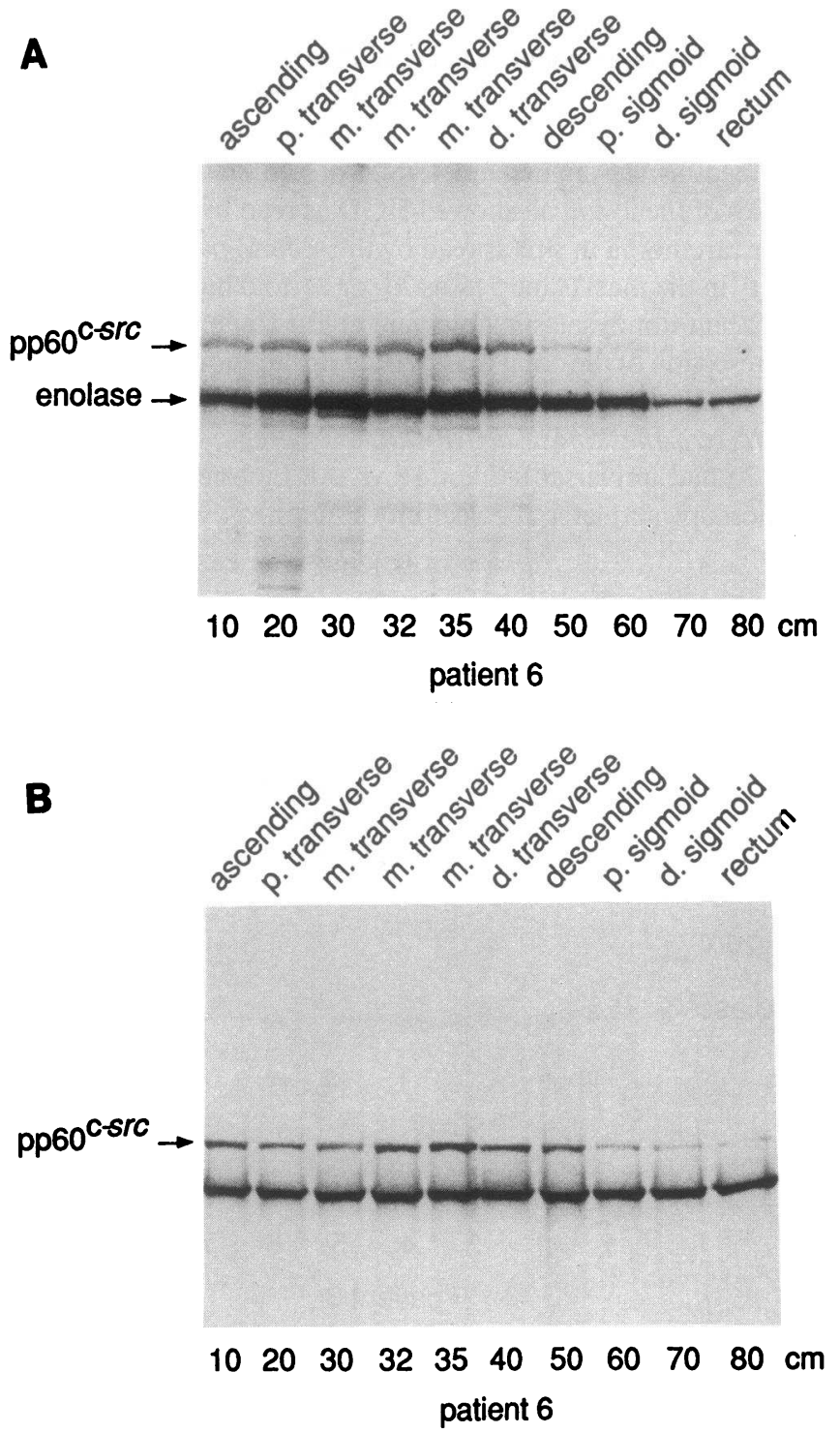

Figure 3. Src tyrosine kinase activity and protein levels in UC carcinoma. Patient 6: 10-60 cm (distance from cecum), HGD; 70-80 $\mathrm{cm}$, LGD; $35 \mathrm{~cm}$, carcinoma. ( $A$ ) Src kinase activity. ( $B)$ Src protein levels. mAb 327 immunoprecipitates, prepared from lysates used for the protein kinase reactions shown in $A$, were resolved by SDS-PAGE and transferred to nitrocellulose. Membranes were incubated with excess $\mathrm{mAb} 327$, washed, and incubated with ${ }^{125} \mathrm{I}$-sheep anti-mouse IgG. Exposure times at $-80^{\circ} \mathrm{C}$ with intensifying screens: $(A) 40 \mathrm{~min}$; (B) 10 h. $p$., proximal; $m$., mid; $d$., distal.

was present in the distal colon ( 70 and $80 \mathrm{~cm}$ from the cecum), and HGD was present in the remainder of the colon. In addition, a sessile $1.5-\mathrm{cm}$ polypoid lesion in the transverse colon $(35 \mathrm{~cm})$, and 1 of 96 lymph nodes examined, contained moderately differentiated adenocarcinoma. The tumor stage was $\mathrm{Cl}$ by the Astler-Coller modification of the Dukes' classification $(24,25)$. Src activity $(A)$ in epithelia containing HGD was higher (on average, fourfold as measured by enolase phosphorylation, or sixfold as measured by autophosphorylation) than Src activity in epithelia containing LGD. Src activity in the carcinoma was 6- or 10-fold higher than that in epithelia containing LGD, and $\sim 2$-fold higher than that in epithelia containing HGD.
Src protein levels (Fig. $3 B$ ) were determined by immunoblot analysis. $\mathrm{mAb} 327$ immunoprecipitates, performed in parallel with those used for the kinase assays shown in Fig. $3 \mathrm{~A}$, were resolved by SDS-PAGE before being transferred to a nitrocellulose membrane. Two proteins were detected in each lane: the upper one is Src, the lower is mAb $327 \mathrm{immunoglobu-}$ lin heavy chain $(12,13)$. Src protein levels were highest in the carcinoma, and higher in epithelia containing HGD than in that containing LGD. Overall, in this patient and in others, Src protein levels correlated with Src kinase activity, and increased protein expression accounted for most of the increased kinase activity.

Patient 7 (Fig. 4) had UC for 15 yr. Multiple biopsies obtained at colonoscopy, and later at colectomy, contained chronic active colitis, and therefore, most were indefinite for dysplasia. A region of flat cecal mucosa was suspicious for HGD, and two, $\leq 0.5 \mathrm{~cm}$, raised lesions in the cecum contained HGD. In addition, a $1.5-\mathrm{cm}$, firm, nodular lesion in the cecum, and 1 of $>50$ lymph nodes examined, contained mucinous adenocarcinoma (Duke's C1). Src activity in either of the high-grade dysplasia-associated lesions or masses (DALMs) was threefold higher than that in flat mucosa containing HGD (compare lanes 2 or 3 with lane 4 ). Src activity in the carcinoma was five- or sevenfold higher (as measured by autophosphorylation or enolase phosphorylation, respectively) than that in HGD (compare lanes 1 and 4 ).

Recently, we examined the tyrosine kinase activity of Srcrelated proteins (Yes, Lck, Fyn, Hck, Lyn, and Fgr) in human colon carcinoma. We observed that c-Yes activity, like that of Src, and unlike that of other family members, was significantly elevated in most carcinomas (26) and in benign adenomas at greatest risk for cancer (C. A. Cartwright, S. Pena, and A. I. Meisler, unpublished observations). Here we measured the protein-tyrosine kinase activity of Yes in the neoplastic UC epithelia of patient 7 (Fig. 4, lanes 5-8). Anti-Yes immunoprecipitates were prepared from those lysates used for the Src protein kinase assays shown in lanes 1-4. We observed that Yes

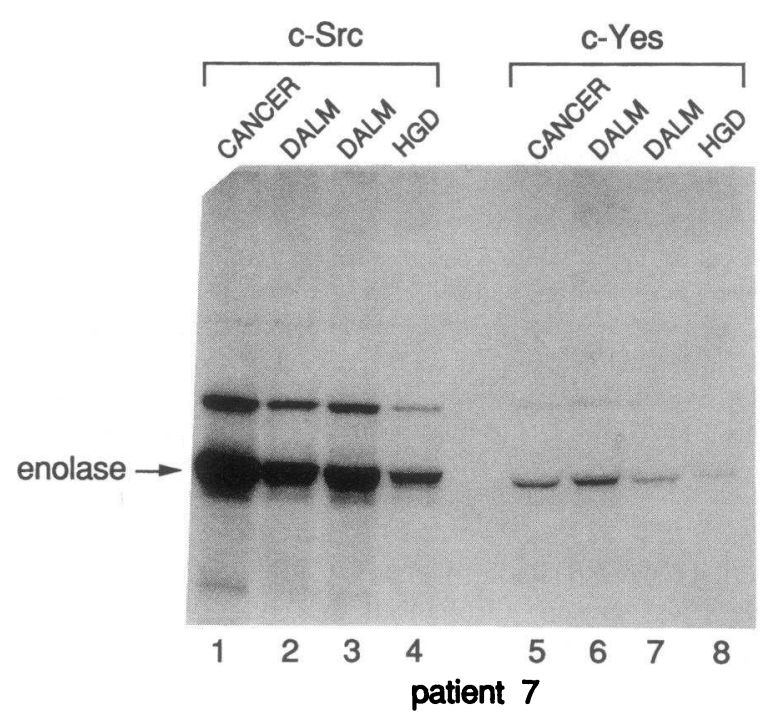

Figure 4. Src and Yes tyrosine kinase activity in UC carcinoma. Patient 7: lanes $l$ and 5, carcinoma; lanes 2, 3, 6, and 7, DALM; lanes 4 and $8, \mathrm{HGD}$ in flat epithelia. Exposure time at $-80^{\circ} \mathrm{C}$ with an intensifying screen: $55 \mathrm{~min}$. 
activity, similar to that of Src, was higher in carcinoma and in DALMs than in flat dysplastic epithelia (compare lanes 5-7 with lane 8 ). As predicted from its molecular mass, Yes (62 $\mathrm{kD})$ migrated more slowly than $\operatorname{Src}(60 \mathrm{kD})$ in the gel. Overall, Src activity was higher than that of Yes in the same epithelia (compare lanes 1-4 with 5-8).

Relative levels of Src tyrosine kinase activity in UC epithelia. Data on Src activity in colonic epithelia from 35 UC patients are summarized in Fig. 5. Values from two to four independent measurements of Src activity were averaged for each sample, and values from different regions of the colon that contained the same histopathology were averaged for each patient. Values shown represent the mean \pm SEM for patients within each group.

Data from those patients who had regions of mild quiescent colitis are shown in Fig. $5 \mathrm{~A}$. Values are expressed relative to those for mild quiescent colitis. Src activity in normal epithelia or in active colitis was similar to that in mild quiescent colitis.
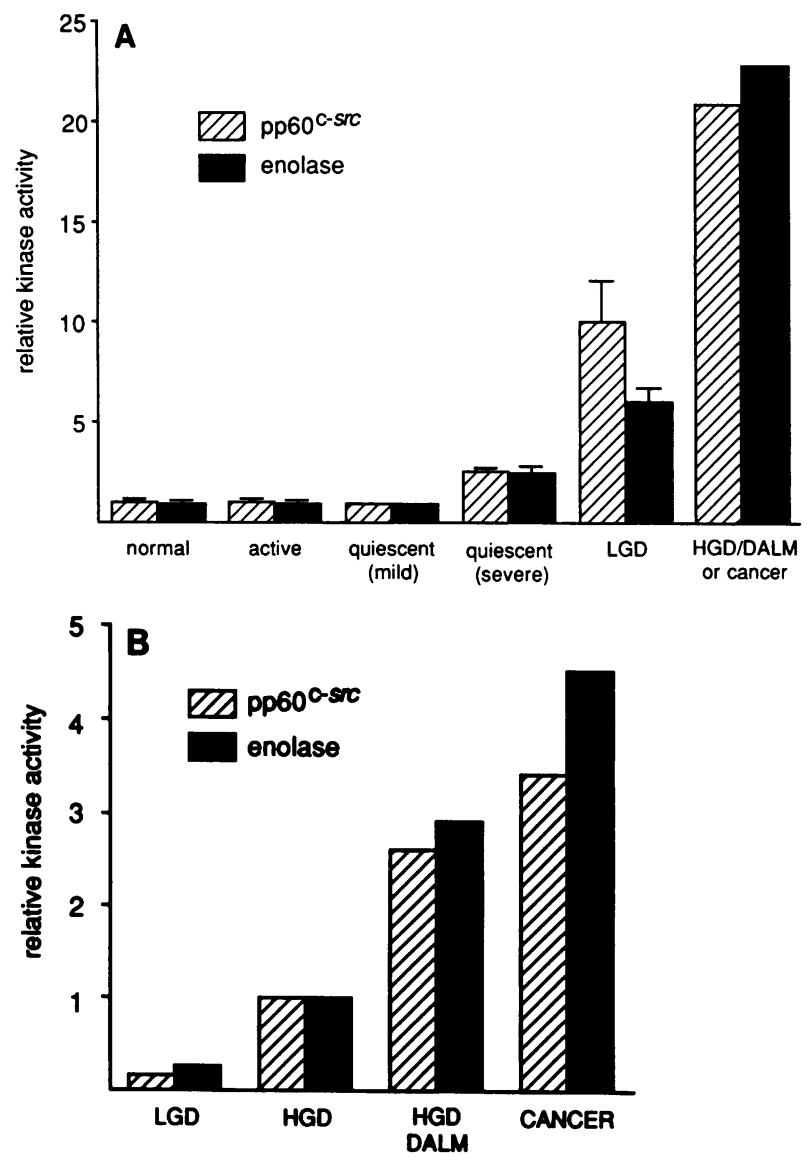

Figure 5. Relative levels of Src tyrosine kinase activity in UC epithelia. $(A) \mathrm{UC}$ patients whose colons contained regions of mild quiescent colitis. LGD, HGD/DALM, or carcinoma in situ (cancer). ( $B$ ) UC patients whose colons contained LGD, HGD, HGD/DALM, and/or invasive carcinoma. ${ }^{32} \mathrm{P}$ incorporation into $\mathrm{Src}$ or enolase was quantified by counting excised gel bands. Values from two to four independent measurements of Src activity were averaged for each sample, and values from different regions of the colon that contained the same histopathology were averaged for each patient. Values shown represent the mean \pm SEM for patients within each group, and are expressed relative to those for mild quiescent colitis $(A)$ or HGD $(B)$. (Hatched bars) Src autophosphorylation; ( solid bars) enolase phosphorylation.
In contrast, Src activity in severe quiescent colitis was higher (2.6-fold as measured by autophosphorylation, or 2.5-fold as measured by enolase phosphorylation ) than that in mild quiescent colitis. Src activity in LGD was 10 - or 6.1-fold higher, and that in HGD/DALM or carcinoma in situ was 20.9- or 22.8fold higher than that in mild quiescent colitis. Thus, Src activity is elevated in dysplastic UC epithelia. In addition, Src activity in nondysplastic severe chronic colitis is significantly higher than that in mild chronic or active colitis, or normal epithelia.

Data from two additional UC patients who had LGD, HGD, DALMs, and carcinomas are summarized in Fig. $5 B$. Because these two patients had no mild quiescent colitis for comparison, their data could not be analyzed with those shown in Fig. $5 \mathrm{~A}$. Values are expressed relative to those for HGD. Src activity in HGD was 6.3- or 3.9-fold higher (as measured by autophosphorylation or enolase phosphorylation, respectively) than that in LGD. Src activity in HGD/DALMs was 2.6- or 2.9-fold higher than that in HGD in flat epithelia. Finally, Src activity in carcinomas was 3.4- or 4.5-fold higher than that in HGD. Thus, the level of Src activity correlates with the degree of dysplasia: the more severe the dysplasia, the higher the Src activity. Moreover, Src activity in HGD-associated lesions is intermediate between that in invasive carcinoma and that in HGD in flat epithelia.

Six patients had active colitis that was indefinite for dysplasia at year 1 , and inactive quiescent colitis that was negative for dysplasia in the same regions of the colon on follow-up evaluation at year 2 (and for two patients, again at year 3 ). In all six patients, Src activity measured in the active colitis at year 1 was very similar to that measured in the inactive colitis in the same region at year 2 (and for the two patients, again at year 3 ). Thus, Src activity remained constant in epithelia that initially were indefinite for dysplasia because of active colitis, and later, when the colitis was quiescent, were clearly and reproducibly negative for dysplasia.

\section{Discussion}

The data show that Src tyrosine kinase activity and protein abundance are elevated in neoplastic UC epithelia. Activity is highest in malignant and severely dysplastic epithelia, and 6-10-fold higher in mildly dysplastic than in nondysplastic epithelia. Thus, Src activity is elevated in premalignant UC epithelia, which is at greatest risk for developing cancer. The data suggest that activation of the src proto-oncogene is an early event in the genesis of UC colon cancer.

Several groups have identified genes whose structure, expression, or activity is altered in different stages of sporadic colon cancer (27). A number of genes are affected relatively late in tumorigenesis, i.e., in carcinomas. These include the putative tumor suppressor genes $\mathrm{p} 53$ and DCC (28-30). Other genes, like the dominant acting oncogene K-ras, seem to be altered earlier in tumorigenesis, in adenomas with a high malignant potential (31). We have shown that the Src and Yes tyrosine kinase activities and protein levels are elevated both in carcinomas and in adenomas $(12,13,26)$. Expression of members of the $m y c$ gene family is abnormal in essentially all adenomas, independent of their malignant potential $(32,33)$. Mutations of the APC locus may represent one of the earliest events in the genesis of colon cancer (34-38).

Src and $m y c$ are overexpressed in many of the same colon carcinomas and adenomas $(12,13,32,33)$. Interestingly, seg- 
ments of fetal rat colon infected with a myc-containing retrovirus and implanted in syngeneic pups develop epithelial atypia and focal dysplasia (14). Segments infected with a v-src-containing retrovirus develop more significant dysplasia throughout the colonic epithelia. Moreover, the segments infected with both oncogenic retroviruses together develop HGD and in one case adenocarcinoma. Thus, $m y c$ and $s r c$ may act synergistically to induce dysplasia.

Genetic alterations in premalignant UC epithelia include p53 point mutations and loss of heterozygosity $(39,40)$, Myc (41), and Src overexpression, and, rarely, ras mutations (4245). p53 inactivation and Src overexpression occur earlier in the histologic progression of neoplasia in UC than in sporadic colon cancer. These observations suggest that the etiology and pathogenesis of sporadic and UC-associated carcinogenesis may differ in significant ways.

Colonic mucosa consists of epithelia and lamina propria. Normally the lamina propria contains lymphocytes, plasma and mast cells, macrophages, eosinophils, and fibroblasts. In quiescent UC, mononuclear cells (predominantly lymphocytes and plasma cells) infiltrate the lamina propria. It is possible that the increased Src activity measured in severe quiescent colitis is actually Src activity measured in these infiltrating cells. However, lymphocytes and plasma cells do not express Src, and macrophages express it at very low levels $(46,47)$. Therefore, it seems unlikely that these cells are contributing significantly to the Src activity in severe quiescent colitis. The cell population in the lamina propria of dysplastic mucosa is not significantly different than that in nondysplastic mucosa, and thus, cannot explain the striking differences observed in Src activity between these mucosae. In active UC, polymorphonuclear cells infiltrate the lamina propria. Again, it is possible that the Src activity measured reflects that found in these acute inflammatory cells. Although the level of Src activity in neutrophils is not known, Src activity measured in active colitis is remarkably similar to that in normal mucosa or mild quiescent colitis (Fig. $5 \mathrm{~A}$ ) despite the varied numbers and types of inflammatory cells present in these different mucosae.

Src protein kinase activity and abundance decrease as human colon carcinoma cell lines differentiate in response to sodium butyrate (48). Moreover, when human colon carcinoma cell lines are treated with herbimycin A (an ansamycin antibiotic that inhibits cellular transformation by retroviral tyrosine kinases) there is a dose-dependent, reversible inhibition of cell growth and a concomitant decrease in Src kinase activity and steady-state protein levels (49). We observed that cytoskeletalassociated Src activity decreases as primary intestinal crypt cells terminally differentiate into enterocytes $(50)$. These results together with those showing elevated Src activity in dysplastic and malignant colonic cells suggest that downregulation of $\mathrm{Src}$ is important for differentiation and upregulation is important for growth and transformation of intestinal epithelial cells.

Possible mechanisms upregulating Src expression in neoplastic colonic epithelia include: protein stabilization, gene overexpression, and/or gene amplification. Preliminary studies indicate that $s r c$ mRNA levels are higher in colon carcinomas than in normal adjacent epithelia (C. A. Cartwright, unpublished observations). Protein overexpression accounts for most but not all of the elevated Src activity in premalignant colonic epithelia. Potential mechanisms upregulating the specific activity of the Src kinase include: dephosphorylation of
Src at Tyr 527, subcellular localization of Src and its substrates, association of Src with other cellular proteins, and genetic mutation in Src (reviewed in reference 8). In cultured colon carcinoma cells, we do not detect decreased phosphorylation of Src at Tyr 527 (12). Preliminary studies indicate that a large fraction of Src and many tyrosine kinase substrates in colon carcinoma cells localize to cellular membranes (K.-Y. Lee and C. A. Cartwright, unpublished observations). Recently, we isolated an Src-associated protein from a $\lambda$ gt 11 expression library of human colon carcinoma cells (Z.-Y. Peng and C. A. Cartwright, unpublished observations). The protein may be important for regulating Src kinase activity.

The recent discovery of widespread mutations in short, repeated DNA sequences in colon cancer reveals a novel mechanism of carcinogenesis distinct from those involving activated oncogenes or inactivated tumor suppressor genes $(51-53)$. The data suggest the presence of a defective DNA replication factor resulting in reduced fidelity for replication or repair. Clearly, multiple, complex molecular mechanisms are involved in colonic carcinogenesis. Activation of the Src tyrosine kinase may be only one of a number of factors contributing to malignant transformation and may not be sufficient in itself to transform cells. Nonetheless, the consistent and striking nature of its activation in malignant and premalignant UC epithelia, together with the strong historical correlate of elevated Src activity and cell transformation, suggest that activation of this kinase may be an important early event in the genesis of UC colon cancer.

\section{Acknowledgments}

We are indebted to Jim Stone, Ed Silverblatt, David Shields, the GI faculty, and the GI endoscopy staff at Stanford University for their help in obtaining tissue samples. We thank Sara Skolnick for technical help with initial experiments, Joan Brugge for providing mAb 327 hybridoma cells, and Sara Courtneidge and Joe Bolen for Yes antisera. We are grateful to Cindi Moothart for help preparing the figures, and Harry Greenberg, Anson Lowe, and Bishr Omary for their critical review of the manuscript.

This work was supported by American Cancer Society grant CD400 (C. A. Cartwright); National Institutes of Health grant R29 DK43743 (C. A. Cartwright); and an American Gastroenterological Association/SmithKline Beecham Clinical Research Award (C. A. Cartwright).

\section{References}

1. American Cancer Society. 1993. Colon and rectum cancer. In Cancer Facts and Figures-1993. American Cancer Society, Atlanta. 10.

2. Ekbom, A., C. Helmick, M. Zack, and H.-O. Adami. 1990. Ulcerative colitis and colorectal cancer. N. Engl. J. Med. 323:1228-1233.

3. Sachar, D. B. 1991. Cancer risk in inflammatory bowel disease: myths and metaphors. In Dysplasia and Cancer in Colitis. R. H. Riddell, editor. Elsevier Science Publishing Co., Inc., New York. 5-9.

4. Bishop, J. M. 1991. Molecular themes in oncogenesis. Cell. 64:235-248.

5. Cantley, L. C., K. R. Auger, C. Carpenter, B. Duckworth, A. Graziani, R. Kapeller, and S. Soltoff. 1991. Oncogenes and signal transduction. Cell. 64:281302.

6. Hunter, T. 1991. Cooperation between oncogenes. Cell. 64:249-270.

7. Hunter, T. 1987. A tail of two src's: mutatis mutandis. Cell. 49:1-4.

8. Cooper, J. A., and B. Howell. 1993. The when and how of Src regulation. Cell. 73:1051-1054.

9. Rosen, N., J. B. Bolen, A. M. Schwartz, P. Cohen, V. DeSeau, and M. A. Israel. 1986. Analysis of pp60 ${ }^{\mathrm{c}-s c c}$ protein kinase activity in human tumor cell lines and tissues. J. Biol. Chem. 26:13754-13759.

10. Bolen, J. B., A. Veillette, A. M. Schwartz, V. DeSeau, and N. Rosen. 1987. Activation of pp60 ${ }^{\text {c-src }}$ protein kinase activity in human colon carcinoma. Proc. Natl. Acad. Sci. USA. 84:2251-2255. 
11. Bolen, J. B., A. Veillette, A. M. Schwartz, V. DeSeau, and N. Rosen. 1987 Analysis of pp60

12. Cartwright, C. A., M. P. Kamps, A. I. Meisler, J. M. Pipas, and W. Eckhart. 1989. pp60 $0^{\text {c-sc }}$ protein kinase is an early event in colonic carcinogenesis. $J$ Clin. Invest. 83:2025-2033.

13. Cartwright, C. A., A. I. Meisler, and W. Eckhart. 1990. Activation of the pp60 $0^{\text {c-src }}$ protein kinase is an early event in colonic carcinogenesis. Proc. Natl. Acad. Sci. USA. 87:558-562.

14. D’Emilia, J. C., B. Mathey-Prevot, K. Jaros, B. Wolf, G. Steele, Jr., and I. C. Summerhayes. 1991. Preneoplastic lesions induced by myc and src oncogenes in a heterotopic rat colon. Oncogene. 6:303-309.

15. Riddell, R. H., H. Goldman, D. F. Ransohoff, H. D. Appelman, C. M Fenoglio, R. C. Haggitt, C. Ahren, P. Correa, S. R. Hamilton, B. C. Morson, S. C. Sommers, and J. H. Yardley. 1983. Dysplasia in inflammatory bowel disease: standardized classification with provisional clinical applications. Hum. Pathol 14:931-968.

16. Lipsich, L. A., A. J. Lewis, and J. S. Brugge. 1983. Isolation of monoclonal antibodies that recognize the transforming proteins of avian sarcoma viruses. $J$. Virol. 48:352-360.

17. Kypta, R. M., Y. Goldberg, E. T. Ulug, and S. A. Courtneidge. 1990 Association between the PDGF receptor and members of the $s r c$ family of tyrosine kinases. Cell. 62:481-492.

18. Cartwright, C. A., R. Simantov, W. M. Cowan, T. Hunter, and W. Eckhart. 1988. pp60 c-src expression in the developing rat brain. Proc. Natl. Acad. Sci. USA. 85:3348-3352.

19. Cartwright, C. A., W. Eckhart, S. Simon, and P. L. Kaplan. 1987. Cell transformation by $\mathrm{pp} 60^{\mathrm{c}-\mathrm{src}}$ mutated in the carboxyl-terminal regulatory domain. Cell. 49:83-91.

20. Cartwright, C. A., R. Simantov, P. L. Kaplan, T. Hunter, and W. Eckhart. 1987. Alterations in pp60 $60^{\text {ssc }}$ accompany differentiation of neurons from rat embryo striatum. Mol. Cell. Biol. 7:1830-1840.

21. Cartwright, C. A., P. L. Kaplan, J. A. Cooper, T. Hunter, and W. Eckhart. 1986. Altered sites of tyrosine phosphorylation in pp60 $0^{\text {c-ssc }}$ associated with polyomavirus middle tumor antigen. Mol. Cell. Biol. 6:1562-1570.

22. Cartwright, C. A., M. Hutchinson, and W. Eckhart. 1985. Structural and functional modifications of pp $60^{\mathrm{c}-s r}$ associated with polyoma middle tumor antigen from infected or transformed cells. Mol. Cell. Biol. 5:2647-2652.

23. Cooper, J. A., F. S. Esch, S. Taylor, and T. Hunter. 1984. Phosphorylation sites in enolase and lactate dehydrogenase utilized by tyrosine protein kinases in vivo and in vitro. J. Biol. Chem. 259:7835-7841.

24. Dukes, C. E. 1932. The classification of cancer of the rectum. J. Pathol. $35: 323$.

25. Astler, V. B., and F. A. Coller. 1954. The prognostic significance of direct extension of carcinoma of the colon and rectum. Ann. Surg. 139:846.

26. Park, J., A. I. Meisler, and C. A. Cartwright. 1993. c-Yes tyrosine kinase activity in human colon carcinoma. Oncogene. 8:2627-2635.

27. Fearon, E. R., and B. Vogelstein. 1990. A genetic model for colorectal tumorigenesis. Cell. 61:759-767.

28. Baker, S. J., E. R. Fearon, J. M. Nigro, S. R. Hamilton, A. C. Preisinger, J. M. Jessup, P. van Tuinen, D. H. Ledbetter, D. F. Barker, Y. Nakamura, R. White, and B. Vogelstein. 1989. Chromosome 17 deletions and $p 53$ gene mutations in colorectal carcinomas. Science (Wash. DC). 244:217-221.

29. Nigro, J. M., S. J. Baker, A. C. Preisinger, J. M. Jessup, R. Hostetter, K. Cleary, S. H. Bigner, N. Davidson, S. Baylin, P. Devilee, T. Glover, F. S. Collins, A. Weston, R. Modali, C. C. Harris, and B. Vogelstein. 1989. Mutations in the p53 gene occur in diverse human tumor types. Nature (Lond.). 342:705-707.

30. Fearon, E. R., K. R. Cho, J. M. Nigro, S. E. Kern, J. W. Simons, J. M. Ruppert, S. R. Hamilton, A. C. Preisinger, G. Thomas, K. W. Kinzler, and B. Vogelstein. 1990. Identification of a chromosome 18q gene that is altered in colorectal cancers. Science (Wash. DC). 247:49-56.

31. Vogelstein, B., E. R. Fearon, S. R. Hamilton, S. E. Kern, A. C. Preisinger, M. Leppert, Y. Nakumura, R. White, A. M. M. Smits, and J. L. Bos. 1988 Genetic alterations during colorectal-tumor development. N. Engl. J. Med. 319:525-32.

32. Finley, G. G., N. T. Schulz, S. A. Hill, J. R. Geiser, J. M. Pipas, and A. I. Meisler. 1989. Expression of the $m y c$ gene family in different stages of human colorectal cancer. Oncogene. 4:963-971.

33. Melhem, M. F., A. I. Meisler, G. G. Finley, W. H. Bryce, M. O. Jones, I. I. Tribby, J. M. Pipas, and R. A. Koski. 1992. Distribution of cells expressing myc proteins in human colorectal epithelium, polyps, and malignant tumors. Cancer Res. 52:5853-5864.

34. Groden, J., A. Thliveris, W. Samowitz, M. Carlson, L. Gelbert, H. Albertsen, G. Joslyn, J. Stevens, L. Spirio, M. Robertson, et al. 1991. Identification and characterization of the familial adenomatous polyposis coli gene. Cell. 66:589600.

35. Joslyn, G., M. Carlson, A. Thliveris, H. Albertsen, L. Gelbert, W. Samowitz, J. Groden, J. Stevens, L. Spirio, M. Robertson, et al. 1991. Identification of deletion mutations and three new genes at the familial polyposis locus. Cell. 66:601-613.

36. Kinzler, K. W., M. C. Nilbert, L.-K. Su, B. Vogelstein, T. M. Bryan, D. B. Levy, K. J. Smith, A. C. Preisinger, P. Hedge, D. McKechnie, et al. 1991. Identification of FAP locus genes from chromosome 5q21. Science (Wash. DC) 253:661-665

37. Nishisho, I., Y. Nakamura, Y. Miyoshi, Y. Miki, H. Ando, A. Horii, K. Koyama, J. Utsunomiya, S. Baba, P. Hedge, et al. 1991. Mutations of chromosome 5q21 genes in FAP and colorectal cancer patients. Science (Wash. DC). 253:665-669.

38. Powell, S. M., N. Zilz, Y. Beazer-Barclay, T. M. Bryan, S. R. Hamilton, S. N. Thibodeau, B. Vogelstein, and K. W. Kinzler. 1992. APC mutations occur early during colorectal tumorigenesis. Nature (Lond.). 359:235-237.

39. Burmer, G. C., P. S. Rabinovitch, R. C. Haggitt, D. A. Crispin, T. A. Brentnall, V. R. Kolli, A. C. Stevens, and C. E. Rubin. 1992. Neoplastic progression in ulcerative colitis: histology, DNA content, and loss of a p53 allele. Gastroenterology. 103:1602-1610.

40. Yin, J., N. Harpaz, Y. Tong, Y. Huang, J. Laurin, B. D. Greenwald, M. Hontanosas, C. Newkirk, and S. J. Meltzer. 1993. p53 point mutations in dysplastic and cancerous ulcerative colitis lesions. Gastroenterology. 104:1633-1639.

41. Ciclitira, P. J., J. C. MaCartney, and G. Evan. 1987. Expression of c-myc in non-malignant and pre-malignant gastrointestinal disorders. J. Pathol. 151:293-296.

42. Burmer, G. C., D. Levine, B. G. Kulander, R. C. Haggitt, C. E. Rubin, and P. S. Rabinovitch. 1990. C-Ki-ras mutations in chronic ulcerative colitis and sporadic colon carcinoma. Gastroenterology. 99:416-420.

43. Meltzer, S. J., S. M. Mane, P. K. Wood, J. H. Resau, C. Newkirk, J. A. Terzakis, B. I. Korelitz, W. M. Weinstein, and S. W. Needleman. 1990. Activation of c-Ki-ras in human gastrointestinal dysplasias determined by direct sequencing of polymerase chain reaction products. Cancer Res. 50:3627-3630.

44. Bell, S. M., S. A. Kelly, J. A. Hoyle, F. A. Lewis, G. R. Taylor, H. Thompson, M. F. Dixon, and P. Quirke. 1991. c-Ki-ras gene mutations in dysplasia and carcinomas complicating ulcerative colitis. Br. J. Cancer. 64:174-178.

45. Chen, J., C. Compton, E. Cheng, F. Fromowitz, and M. V. Viola. 1992. c-Ki-ras mutations in dysplastic fields and cancers in ulcerative colitis. Gastroenterology. 102:1983-1987.

46. Bolen, J. B. 1991. Signal transduction by the Src family of tyrosine kinases in hemopoietic cells. Cell Growth \& Differ. 2:409-414.

47. Bolen, J. B., P. A. Thompson, E. Eiseman, and I. D. Horak. 1991. Expression and interactions of the Src family of tyrosine protein kinases in T lymphocytes. Adv. Cancer. Res. 57:103-149.

48. Foss, F. M., A. Veillette, O. Sartor, N. Rosen, and J. B. Bolen. 1989. Alterations in the expression of pp60 $0^{\text {cssc }}$ and $\mathrm{p} 56^{\text {lck }}$ associated with butyrate-induced differentiation of human colon carcinoma cells. Oncogene Research. 5:1323.

49. Garcia, R., N. U. Parikh, H. Saya, and G. E. Gallick. 1991. Effect of herbimycin A on growth and pp60 $0^{\text {c-src }}$ activity in human colon tumor cell lines. Oncogene. 6:1983-1989.

50. Cartwright, C. A., S. Mamajiwalla, S. A. Skolnick, W. Eckhart, and D. R. Burgess. 1993. Intestinal crypt cells contain higher levels of cytoskeletal-associated pp $60^{c-s r c}$ protein tyrosine kinase activity than do differentiated enterocytes. Oncogene. 8:1033-1039.

51. Peltomäki, P., L. A. Aaltonen, P. Sistonen, L. Pylkkänen, J.-P. Mecklin, H. Järvinen, J. S. Green, J. R. Jass, J. L. Weber, F. S. Leach, et al. 1993. Genetic mapping of a locus predisposing to human colorectal cancer. Science (Wash. DC). 260:810-812.

52. Aaltonen, L. A., P. Peltomäki, F. S. Leach, P. Sistonen, L. Pylkkänen, J.-P. Mechlin, H. Järvinen, S. M. Powell, J. Jen, S. R. Hamilton, et al. 1993. Clues to the pathogenesis of familial colorectal cancer. Science (Wash. DC). 260:812816.

53. Ionov, Y., M. A. Peinado, S. Malkhosyan, D. Shibata, and M. Perucho. 1993. Ubiquitous somatic mutations in simple repeated sequences reveal a new mechanism for colonic carcinogenesis. Science (Wash. DC). 363:558-561. 